\title{
COMPARATIVE STUDY OF HYBRID AND CASCADED H-BRIDGE MULTILEVEL INVERTERS
}

\author{
M. Dileep Krishna ${ }^{1}$, Shelly Vadhera ${ }^{2}$ \\ ${ }^{I}$ M.Tech. Student, ${ }^{2}$ Assistant Professor, Electrical Engineering Department, NIT Kurukshetra, Kurukshetra \\ dileepkrishnaeee@gmail.com
}

\begin{abstract}
In this paper comparative study of proposed hybrid multilevel inverter (HMI) operating in modified pulse width modulation (PWM) mode with cascaded H-bridge multilevel inverter (CHMI) is done. Two types of HMIs are proposed with same configuration. To control the two HMIs, modified PWM techniques are derived from sinusoidal pulse width modulation (SPWM) to reduce the switching losses in the inverter. Matlab/Simulink models are used to study the output of HMI and CHMI.
\end{abstract}

Index Terms:- Cascaded H-bridge multilevel inverter, Hybrid multilevel inverter, Pulse width modulation, Total harmonic distortion (THD)

\section{INTRODUCTION}

Multilevel inverters (MLI) are becoming popular than two level inverter in high power applications. Multilevel output is synthesized by small dc voltage levels. In multilevel inverters all the switches are connected in series which allows operation at higher voltage level [1]. The main advantages of MLI are high voltage capability, low switching losses, low dv/dt, less THD, less electromagnetic compatibility [1-2].

The main three MLI configurations are neutral point converter, flying capacitor and cascaded H-bridge multilevel inverter [3]. CHMI has more advantages than other two mentioned. CHMI does not have flying capacitors and clamping diodes. Main drawback of CHMI is that the number of devices used increases with the number of levels [4] and this increases the gate drive circuits at control stage itself causing high cost and switching losses [5]. To overcome above disadvantages the choice is hybrid multilevel inverter which is derived from cascaded H-bridge inverter. In order to control the MLI output voltage there are several control techniques in the literature. The most efficient methods are based on sinusoidal PWM techniques because it leads to easy control of inverter's fundamental voltage and as well as eliminates the harmonics. Among various PWM techniques, phase disposition sinusoidal pulse width modulation (PDSPWM) technique is most popular because of its simplicity to apply in CHMI and HMI control with increase in number of levels [6].

\section{HYBRID MULTILEVEL INVERTER}

Proposed HMI is derived from conventional CHMI as shown in Fig.1. It consists of one main inverter and auxiliary inverters. These are cascaded to get the multilevel output. Main inverter consists of two switching devices cascaded to conventional H-bridge inverter which consists of four switching devices. For five level HMI total six devices are required in each phase of a three phase connection which reduces number of devices by six as compared to three phase five level CHMI [7-8].
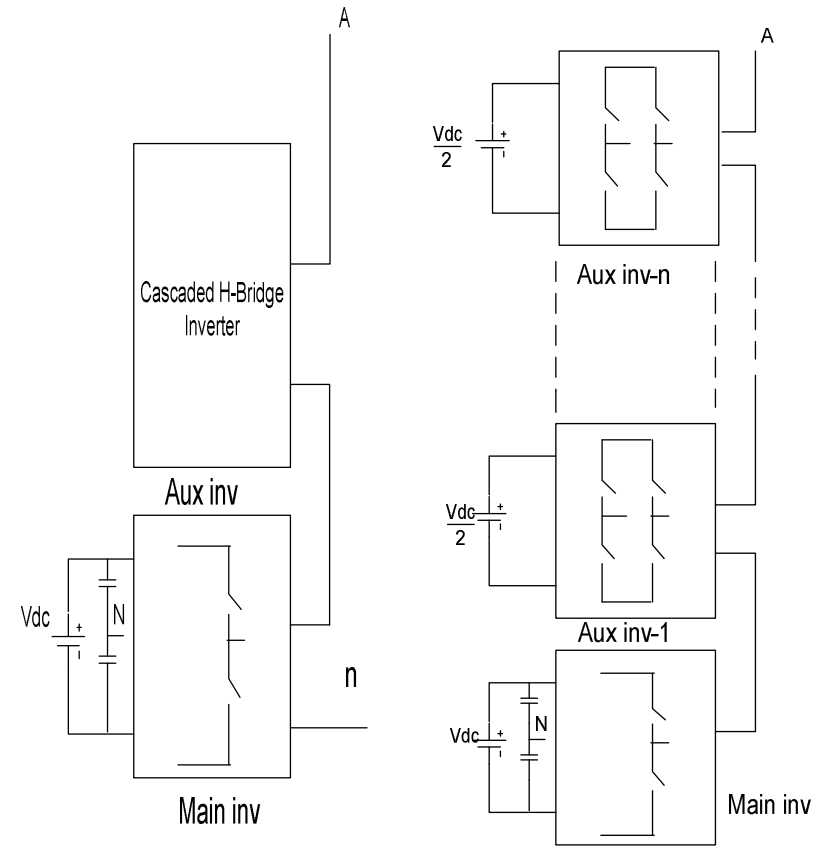

Fig.1 Proposed hybrid multilevel inverter configuration. 
For n level CHMI (n-1)/2 number of independent sources are required. In general independent sources may be renewable energy sources like same rated solar panels or fuel cells or wind energy sources [9].

Seven level HMI is configured as shown in Fig.2. It consists of three inverters namely main inverter, auxiliary inverter-I and auxiliary inverter-II in cascaded mode.

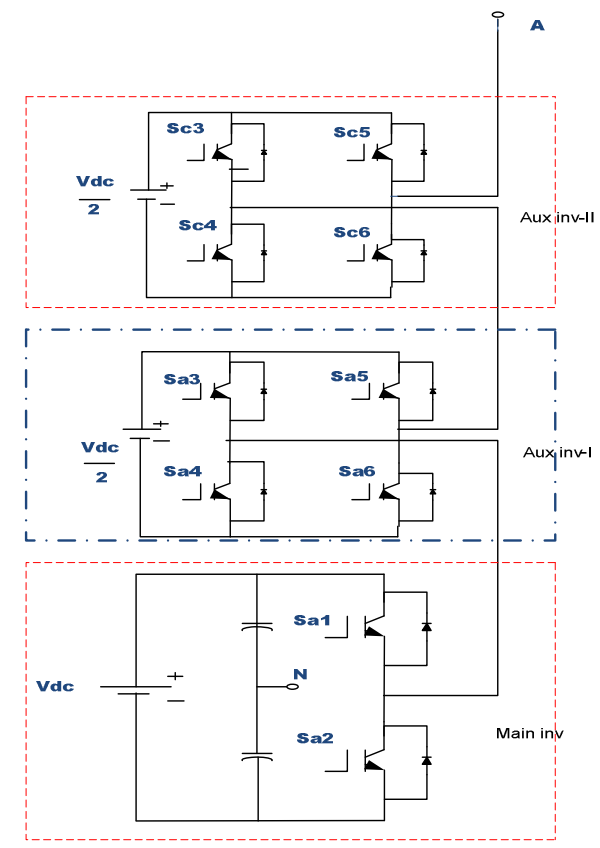

Fig.2 Seven level hybrid multilevel inverter configuration.

\section{PROPOSED TYPES OF HMI}

Since carrier PWM techniques are used in the control of HMI, high frequency switches are required in each stage. As the number of high frequency switching devices increases, the reliability of the inverter reduces. Moreover the high frequency switches are expensive [10] and henceforth the number of high frequency switching devices used in the current path of the inverter should be reduced to avoid rapid switching which leads to reduction of the losses in the inverter. The inverters if operated in square wave mode at fundamental frequency allow the use of low frequency switches and thus cause reduction in the cost of the switches. Keeping these in view two types of HMI are explained. In these two types of inverters the circuit configuration of HMI is kept same and only the number of high frequency and low frequency switches in the inverter is varied.

\subsection{Type I:-Operating One Inverter in PWM Mode} and Remaining Inverters in Square Wave Mode.

In this type of operation auxiliary inverter-I is operating in PWM mode and remaining auxiliary inverters and main inverter are operating in square wave mode. An advantage of operating in square wave mode is that the low frequency switches which operate at fundamental frequency can be used. Whereas only one inverter i.e auxiliary inverter-I is operating in PWM mode. This type requires four high frequency switches in any level of single phase inverter and thus finally the total cost of switching devices is reduced. The control scheme for this type is explained as following:

To control the hybrid inverter satisfactorily the modified PWM technique is derived from conventional SPWM technique, which decreases the losses in the inverter [11].

Control signals of PWM and square wave inverters are fabricated by using equations from $(1-4)$ and are shown in Fig.3.

$f(t)=m_{a} \operatorname{Sin}(\omega t)$

$\frac{\mathrm{T}_{\mathrm{p}}}{\mathrm{T}_{\mathrm{c}}}= \begin{cases}\mathrm{f}(\mathrm{t}) & ; \sin \left(\frac{\pi}{2 *(\mathrm{n}-2)}\right) \leq|\mathrm{f}(\mathrm{t})| \leq 1 \\ \left(1-\frac{\mathrm{f}(\mathrm{t})}{\sin \left(\frac{\pi}{2 *(\mathrm{n}-2)}\right)}\right) ; 0 \leq|\mathrm{f}(\mathrm{t})| \leq \sin \left(\frac{\pi}{2 *(\mathrm{n}-2)}\right)\end{cases}$

$A_{1}=\left\{\begin{array}{l}1 ; f(t) \geq 0 \\ 0 ; f(t)<0\end{array}\right.$

$A_{2}=\left\{\begin{array}{l}1 ;|f(t)| \geq \sin \left(\frac{\pi}{2 *(n-2)}\right) \\ 0 ;|f(t)|<\sin \left(\frac{\pi}{2 *(n-2)}\right)\end{array}\right.$

Where,

$\mathrm{f}(\mathrm{t})$ reference signal,

$\mathrm{N}$ number of levels,

ma modulation index (0-1.0),

A1 multiplexing signal1,

A2 multiplexing signal2,

$\frac{\mathrm{T}_{\mathrm{p}}}{\mathrm{T}_{\mathrm{c}}} \quad$ pulse width of PWM (0-1). 


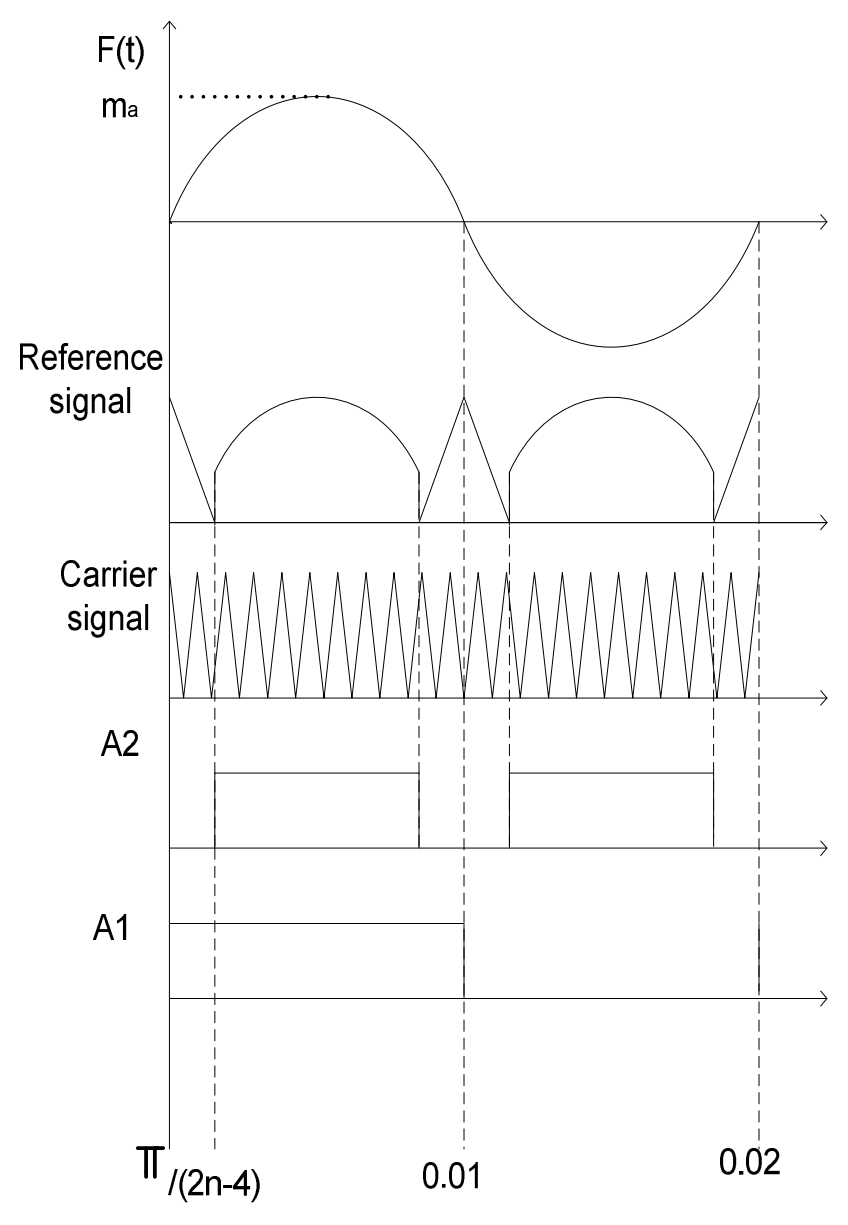

Fig3 Waveforms of PWM and multiplex signals

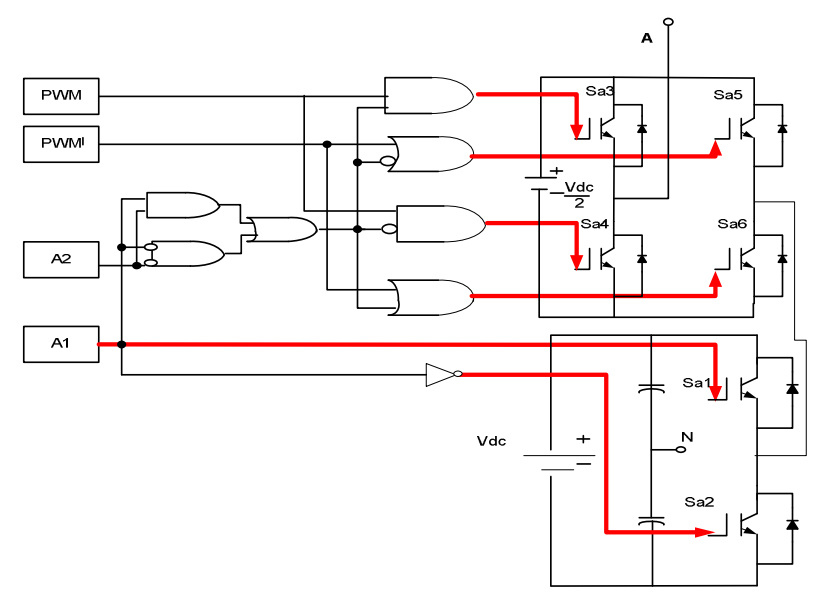

a)

Volume: 02 Issue: 08 | Aug-2013, Available @ http://www.ijret.org

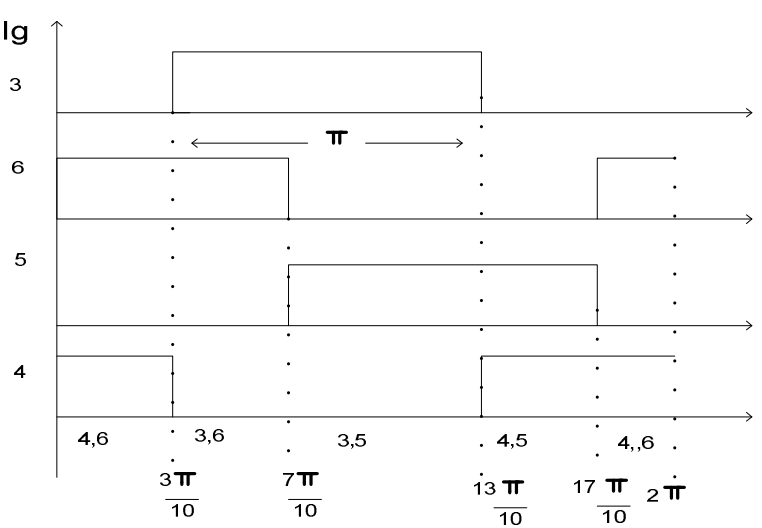

b)

Fig4 a)Logic diagram. b) Gate signals of Auxiliary inverter-II.

Auxiliary inverter-II is operated in square wave mode. Its gate signals and the logic diagram of auxiliary inverter-I are shown in Fig.4. The seven level output of inverter is obtained by three stage inverters as shown in Fig.5.

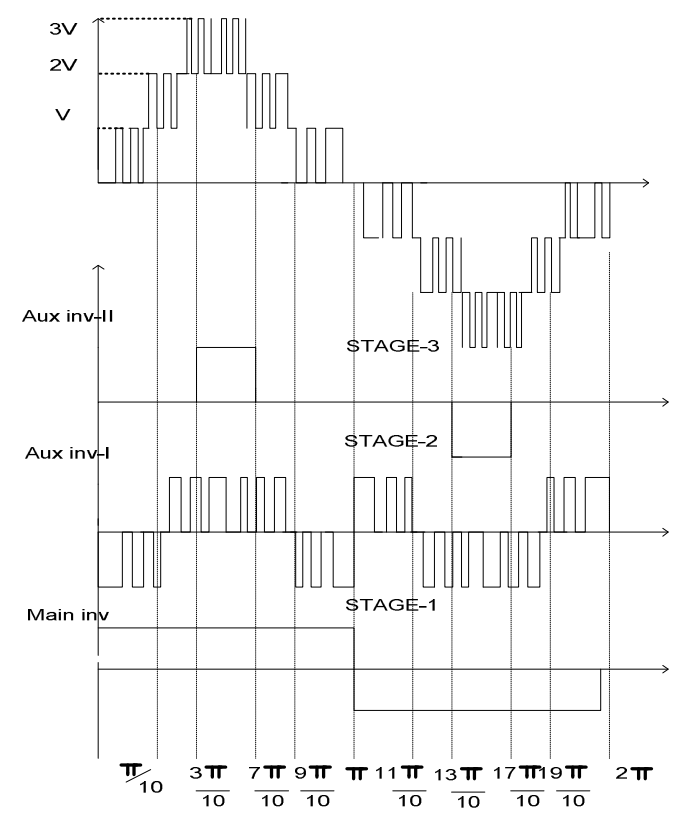

Fig5: Output of seven level inverter

For $n$ level inverter $m$ stages are required. Where $n=2 m+1$, $\mathrm{m} \geq 2$ and $\mathrm{m}$ number of dc sources are required. Main inverter is connected to $\mathrm{Vdc}=310 \mathrm{~V}$ voltage where as auxiliary inverters are operated with $\mathrm{Vdc} / 2=155 \mathrm{~V}$ voltage. Conduction periods of auxiliary inverters in $\mathrm{n}$ level HMI are given in the Fig. 6. 


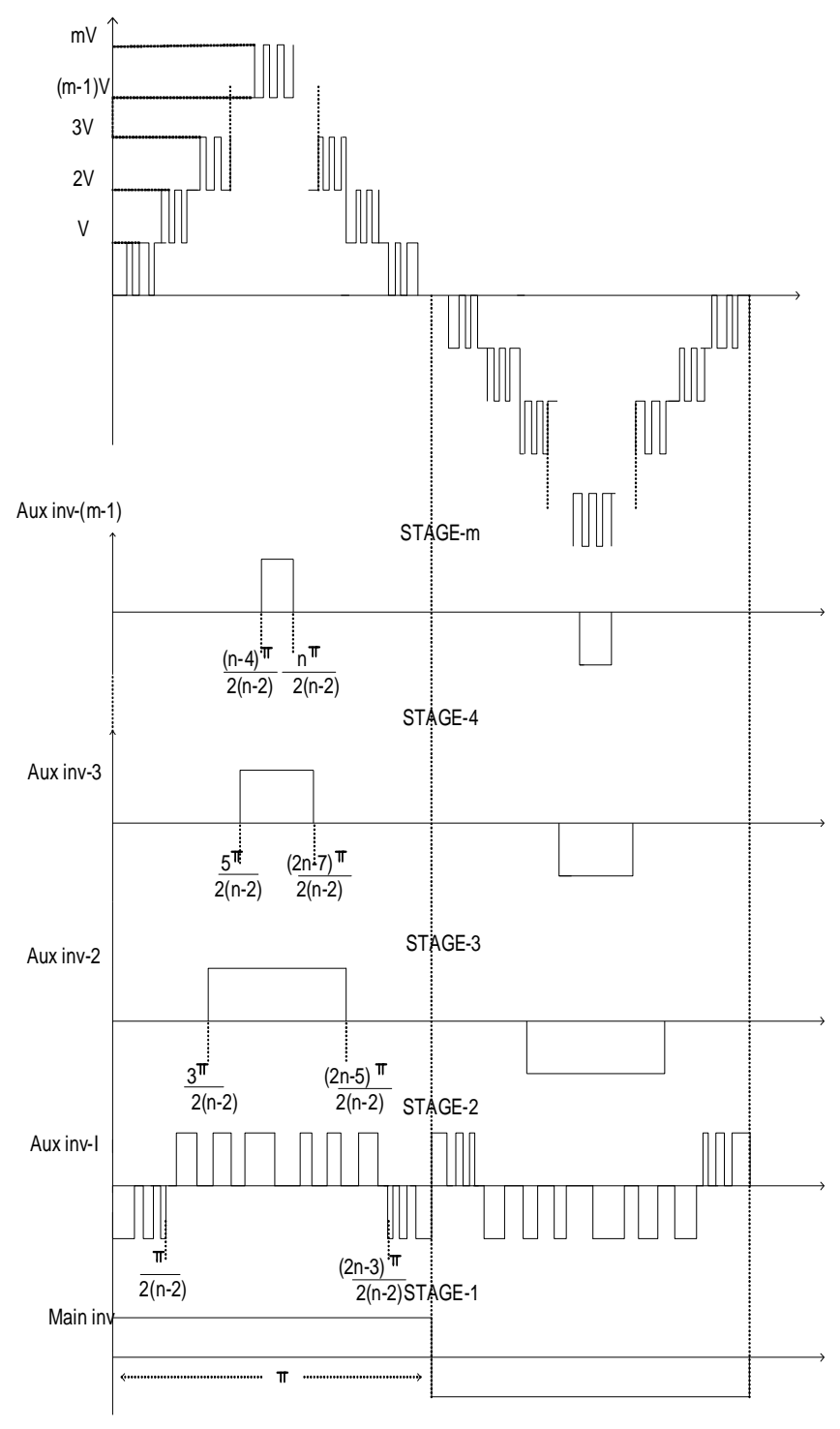

Fig.6 Output of n level inverter.

Matlab/Simulink model is used to study the output of inverter. Simulation results are given in the Fig.7.

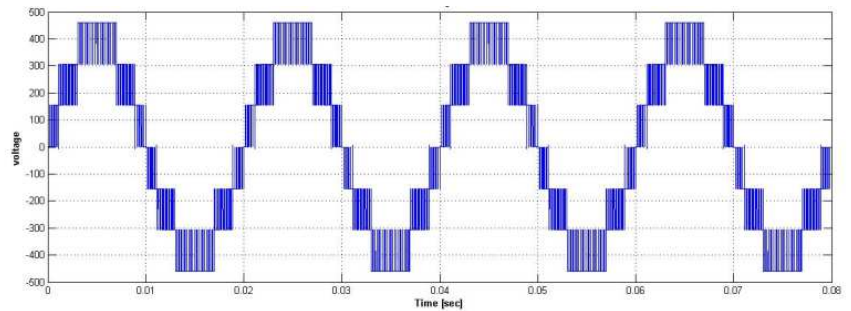

a)

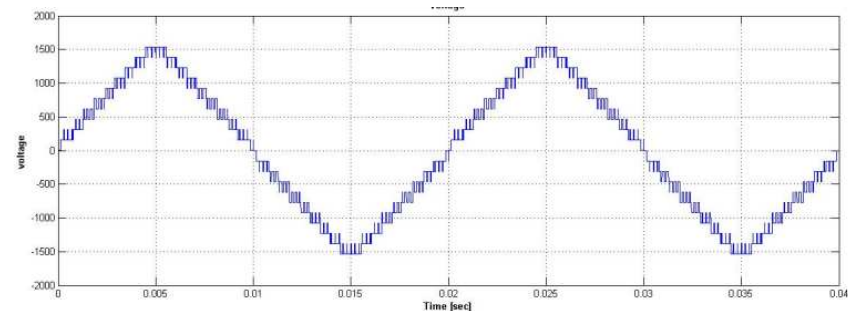

b)

Fig.7 a) Simulation result of seven level inverter b) Output of twenty one level inverter

From the simulation results it is observed that in this type of inverter operation as the number of levels increases the output wave gets distorted from the required sinusoidal shape which results in higher THD. Second type of inverter is preferable in higher level HMI.

\subsection{Type II:-Operating One Inverter in Square Wave} Mode and Remaining Inverters in PWM Mode.

In this type the main inverter is operating in square wave mode and auxiliary inverters are operating in PWM mode. Even when the main inverter is operating with low frequency switches the final output voltage profile obtained is better than the type-I. Control signals for auxiliary inverters are given by modified PDSPWM (MPDSPWM) technique which is derived from conventional PDSPWM. The main difference between these two techniques lies in reference signal and magnitude of carriers.

For n level HMI, control signals of all auxiliary inverters from auxiliary inverter-II onwards are derived by using (m-1) carrier signals above the reference with level shifted, same frequency and one reference signal as given in equation (5) to generate PWM signals in the positive half of inverter output. Another (m-1) level shifted carrier signals are below the zero reference and then the same reference signal is required in negative half of the control signal as shown in Fig.8.

$r(t)=\left(\frac{\mathrm{f}(\mathrm{t})}{\sin \left(\frac{\pi}{2 *(\mathrm{n}-2)}\right)}-1\right) ; \sin \left(\frac{\pi}{2 *(\mathrm{n}-2)}\right) \leq \mathrm{f}(\mathrm{t}) \leq$
$-\sin \left(\frac{\pi}{2 *(\mathrm{n}-2)}\right)(5)$

Where,

$f(t)$ reference signal given in equation (1),

n number of levels,

$r(t)$ Reference signal in MPDSPWM.

Control signals for auxiliary inverter-I and main inverter are derived by using same logic circuit as explained in type-I with the reference signal in equation (2) modified to equation (6). 
$\frac{\mathrm{T}_{\mathrm{p}}}{\mathrm{T}_{\mathrm{c}}}= \begin{cases}\left(\frac{\mathrm{f}(\mathrm{t})}{\sin \left(\frac{\pi}{2 *(\mathrm{n}-2)}\right)}-1\right) & ; \sin \left(\frac{\pi}{2 *(\mathrm{n}-2)}\right) \leq|\mathrm{f}(\mathrm{t})| \leq 1 \\ \left(1-\frac{\mathrm{f}(\mathrm{t})}{\sin \left(\frac{\pi}{2 *(\mathrm{n}-2)}\right)}\right) & ; 0 \leq|\mathrm{f}(\mathrm{t})| \leq \sin \left(\frac{\pi}{2 *(\mathrm{n}-2)}\right)\end{cases}$

(6)

Where,

$f(t) \quad$ reference signal given in equation (1),

$\mathrm{n}$ number of levels,

$\underline{T_{p}} \quad$ pulse width of PWM (0-1).

$\frac{\mathrm{T}_{\mathrm{c}}}{\mathrm{T}}$

Twenty one level HMI simulation results are given in Fig.9.

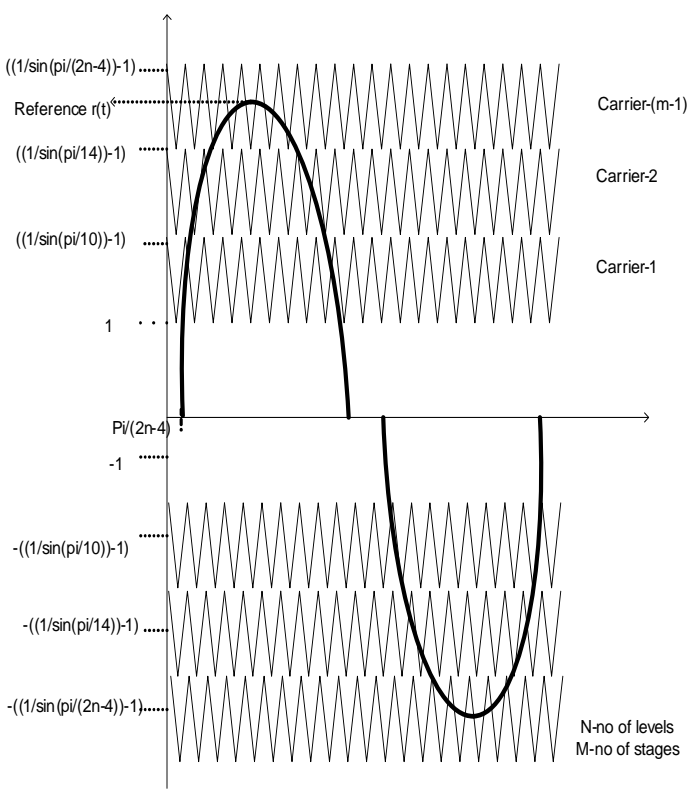

Fig.8 Control signals with modified PDSPWM.

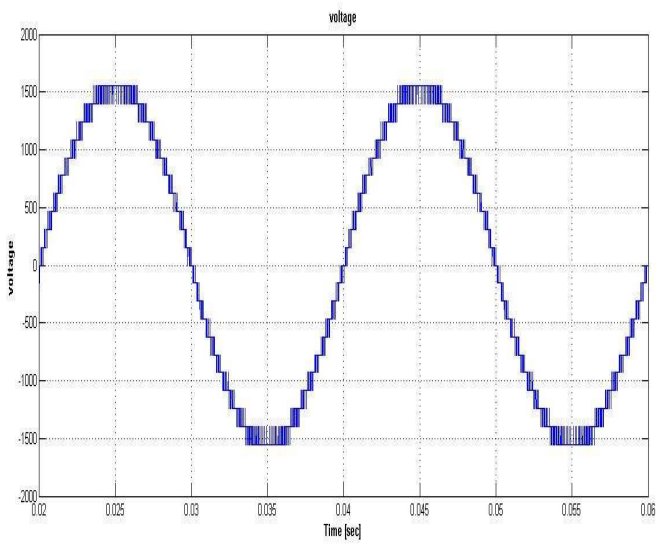

Fig.9 Output of twenty one level HMI.

\section{COMPARISON OF HMI WITH CHMI}

Matlab/simulink models are used to study the HMI and CHMI. The output THD and RMS (root mean square) voltage variation with change in level are given in the Fig.10 \& Fig.11. HMI-I and HMI-II indicates type-I and type-II respectively. From the results it is observed that with HMI as the number of level increases more than seven then HMI-II is preferred. From THD curves shown in Fig.10 it is observed that HMI-II with MPDSPWM gives the less THD as compared to CHMI with PDSPWM of the same level. From the RMS output voltage versus level chart as shown in Fig.11 it is evident that up to thirteen levels HMI-II gives high RMS voltage as compared to CHMI. Number of high frequency switches used in HMI depends on type of operation. For single phase in type-I only four switches are operated in PWM mode and remaining switches are low frequency switches which are operated at fundamental frequency for any level of output.

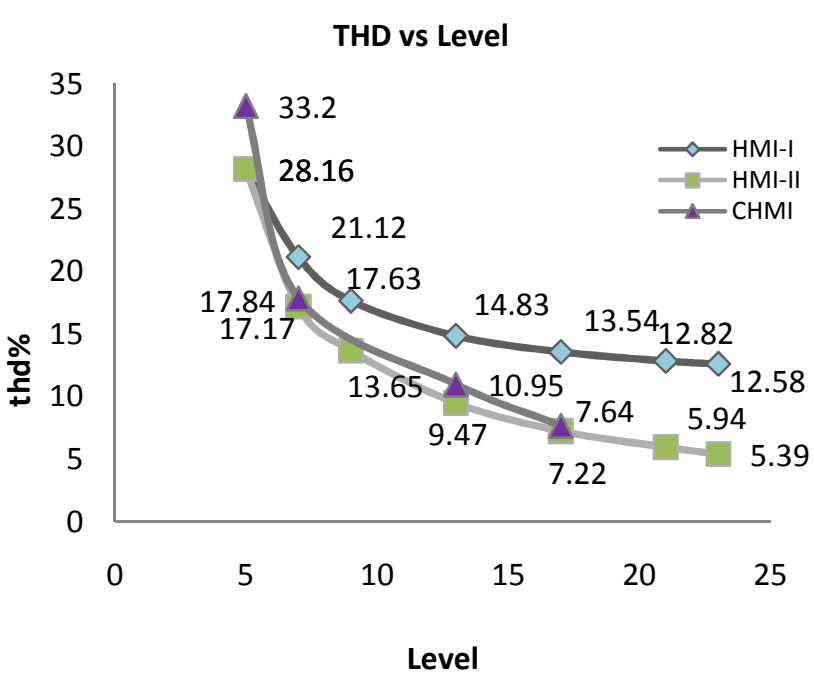

Fig.10 THD variation with increase in level in HMI and CHMI

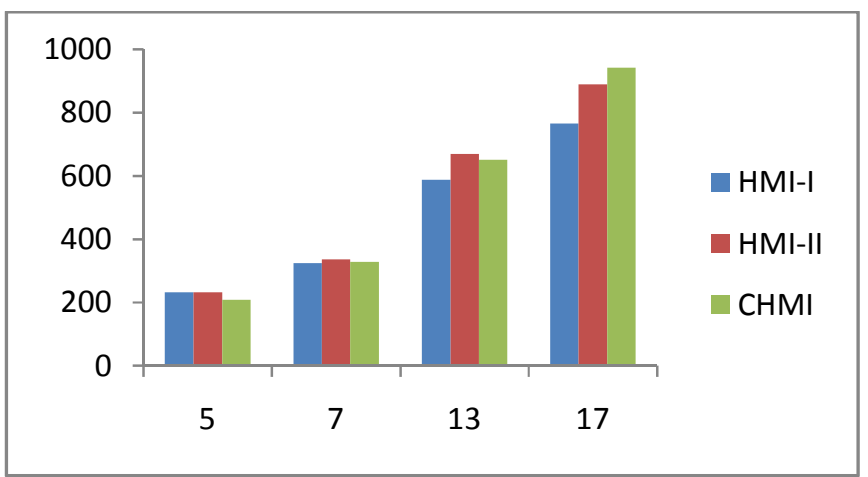

Fig.11 RMS output voltage variation in HMI and CHMI with multi level 
To get seven level output HMI-I is preferred since it uses four high frequency switches and six low frequency switches per phase where as HMI-II uses eight high frequency and two low frequency switches and CHMI uses twelve high frequency switches per phase. In seven level inverter operation even though THD of HMI-I is high as compared to HMI-II and CHMI, cost can be reduced because of using high number of low frequency switches and reliability can be increased since only two high frequency switches are operated in current path of inverter. Up to thirteen levels HMI-II gives high RMS output voltage and less THD as compared to CHMI. Above this level even though THD is less in HMI-II but CHMI gives high RMS output voltage and almost same value of THD.

\section{CONCLUSIONS}

In this paper comparative study of proposed HMI with CHMI is done. Matlab/simulink models are used for analysis purpose. Mainly two types of HMI are explained with modified PWM techniques. HMI-II with modified phase disposition sinusoidal pulse width modulation gives low THD as compared to CHMI of same level output. HMI-I uses only two high frequency switches in current path of inverter and four high frequency switches for any level output so it is more reliable and cost efficient model but for higher levels its THD and output RMS voltage is poor. So type-I i.e HMI-I is preferable up to seven levels above seven level HMI-II is preferred. This paper highlights the advantages of HMI in lower levels in contrast to CHMI and thereby establishes the application of HMI to be interfaced easily with renewable energy sources like wind and solar hybrid generating systems.

\section{REFERENCES}

[1] N. Mohan, T. M Undeland, "Power electronicsconverters, applications and design," $3{ }^{\text {rd }}$ Edition, John Wiley \& Sons, New York, 2003.

[2] K. Jang-Hwan, "A carrier based PWM method with optimal switching sequence for a multi level four-leg voltage source inverter," IEEE Trans. Ind. Applications, vol. 44, pp.1239-1248, 2008.

[3] Muhammad H. Rashid, "Power electronics, circuits, devices and applications," $3^{\text {rd }}$ Edition, Pearson-Prentice Hall, 2004.

[4] T. Porselvi, M. Ranganath, "Comparison of cascaded H-Bridge, neutral point clamped and flying capacitor multilevel inverters using multicarrier PWM", IEEE India Conference (INDICON), pp. 1-4, 16-18 Dec. 2011.J. Rodriguez, J. S. Lai, and F. Z. Peng, "Multilevel inverters: A survey of topologies, controls and applications," IEEE Trans. Ind. Electron, vol. 49, no. 4, pp. 724-738, Aug. 2002.

[5] D. Sreenivasarao, Pramod Agrawal and B. Das, "A carrier-transposed modulation technique for multilevel inverters," Power Electronics, Drives and Energy Systems (PEDES), pp. 1-7, 20-23 Dec. 2010.
[6] Khomfoi and A. Chatrchai, "A 5-level cascaded hybrid multilevel inverter for interfacing with renewable energy resources", International Conference on Electrical Engineering/Electronics, Computer, Telecommunications, and Information Technology, (ECTI-CON 2009), Pattaya, Thailand, vol. 1, pp. 284287, 6-9 May 2009.

[7] Surin Khomfoi and Nattapat Praisuwanna, "A hybrid cascaded multilevel inverter for interfacing with renewable energy resources", International Power Electronics Conference (IPEC), pp. 2912 - 2917, 2010.

[8] M. Dileep Krishna and Shelly Vadhera, "Application of hybrid multilevel inverter in wind and photo voltaic generating systems", National conference on Recent Trends In Energy, Systems And Control (RTESC-13), pp. 5-9, 15-16 March 2013.

[9] M. D. Manjrekar, P. Steimer and T. A. Lipo, "Hybrid multilevel power conversion system: a competitive solution for high power applications", IEEE Trans. on Industry Applications, vol. 36, no. 3, pp. 834-841, May/June 2000.

[10] Khomfoi and L. M. Tolbert, "Multilevel power converters", Power Electronics Handbook, 2nd Edition Elsevier, 2007. 